\title{
ANGIOTENSIN II INDUCED EXPRESSION OF TRANSCRIPTION FACTORS Precedes InCRease in Transforming Growth Factor- $\beta 1$ MRNa in Neonatal Cardiac Fibroblasts
}

H.S. Sharma $\#^{*}$, H.A.A. van Heugten§, M.A. Goedbloed I, P.D. Verdouwl, and J.M.J. Lamers§

Departments of 1 Experimental Cardiology (Thoraxcenter), \#Pharmacology and $\S_{\text {Biochemistry, }}$ Faculty of Medicine and Health Sciences, Erasmus University, 3000 DR Rotterdam, The Netherlands

Received September 12, 1994

Angiotensin II (ANG II), a potent vasoconstricting peptide, may act as a growth factor for cardiac muscle cells and induce hypertrophy. We examined the molecular phenotype of neonatal rat cardiac fibroblasts in relation to ANG II by studying the expression pattern of three transcription factors (Egr-1, c-fos and c-jun) and the transforming growth factor- $\beta 1$ (TGF- $\beta 1$ ). ANG II did not affect cell proliferation and growth of serum deprived neonatal cardiac fibroblasts as predicted from their DNA and protein contents. The expression of Egr-1 and c-fos was induced as early as 15 min that reached maximal levels at $45 \mathrm{~min}$ and declined thereafter, whereas c-jun was induced at $45 \mathrm{~min}$ and remained elevated up to $2 \mathrm{hrs}$ of ANG II addition. ANG II up-regulated the expression of TGF- $\beta 1$, which became apparent after $1 \mathrm{hr}$ of incubation and reached a plateau between $16-48 \mathrm{hrs}$. Our results indicate that ANG II transiently stimulates the expression of transcription factors, which may up-regulate TGF- $\beta 1$, that in turn could contribute to the process of myocardial extra-cellular matrix remodeling in hypertrophy. 1994 Academle Press, Inc.

Angiotensin II (ANG II), the effector octapeptide and circulating hormone of the reninangiotensin system plays an important role in regulating the cardiovascular homeostasis 1 . ANG II is a potent vasoconstrictor which may also act as a growth factor for a wide variety of cells including cardiac fibroblasts ${ }^{2-4}$. ANG II can bind to the cell surface specific receptors (AT 1 subtype) which have been shown to be present on cardiac fibroblasts as well as on cardiomyocytes recently ${ }^{5-7}$, but the intracellular mediators of the growth promoting action of ANG II are not yet fully characterized. It is known that ANG II induced cardiac hypertrophy is often accompanied by fibrosis, defined by proliferation of interstitial fibroblasts and biosynthesis of extracellular matrix components like fibronectin and collagens 8.9 . In culture, ANG II induces

*To whom correspondence should be addressed. Fax: $+31-10-4366839$.

Abbreviations: ANG II, angiotensin II; TGF- $\beta 1$, transforming growth factor- $\beta 1$; TFs, transcription factors; IE, immediate early; PI, phosphatidylinositol phosphate; ATCC, American type culture collection; ANF, atrial natriuretic factor; $\beta$-MHC, $\beta$-myosin heavy chain. 
hypertrophy of cardiomyocytes and vascular smooth muscle cells, as it was shown by an increased rate of protein synthesis $3,4,10$.

Growth and differentiation factors usually stimulate the expression of immediate-early (IE) genes called nuclear proto-oncogenes that include the FOS family ${ }^{11}$, JUN family 12 and the EGR family (Egr-1, Egr-2, Egr-3) 3,13-15. These genes encode for putative transcription factors (TFs) which on their turn are believed to regulate the nuclear transcriptional machinery during a growth factor stimulation and thereby influence cellular growth and differentiation ${ }^{14-16}$. For instance, Egr-1, in analogy to the other proto-oncogenes mentioned above is a nuclear signal transducer which couples early biochemical events to the long term changes in cellular phenotype through modulation of gene expression 15,17 . Enhanced expression of IE genes has been reported in various in vivo and in vitro models of cardiac hypertrophy3,15,18-21. TGF- $\beta 1$, an important factor in cardiac ontogeny and adaptation, plays a crucial role in the growth of vascular smooth muscle cells and fibroblasts and in stimulation of extracellular matrix components like collagens and fibronectin production in response to ANG II $4,8,22,23$. Recently it has been shown that ANG II induces the expression of various IE genes as well as TGF- $\beta 1$ in cultured cardiomyocytes ${ }^{3,19}$. However, it is not known whether ANG II can modulate the expression of TGF- $\beta 1$ in neonatal cardiac fibroblasts. Therefore, to examine the intracellular mediators of ANG II-induced molecular responses in neonatal rat cardiac fibroblasts, we studied the expression pattern of three transcription factors, namely Egr-1, c-fos and c-jun and of the growth factor, TGF- $\beta 1$ in these cells incubated with the [ $\left.\mathrm{Sar}^{1}\right]-$ ANG II, a protease resistant analog of ANG II.

\section{Materials and Methods}

\section{Preparation and culture of neonatal rat cardiac fibroblasts}

Ventricular fibroblasts were isolated by enzymatic dissociation of cardiac tissue from 2-3 days old Wistar strain rat pups according to the methods described earlier $5,24,25$. For the isolation of each cell batch, 30-40 neonatal hearts were rapidly excised from decapitated animals, minced and treated with a solution of trypsin (type III, Sigma Chemie, Belgium). After repeated digestion steps, the collected cells in suspension were centrifuged. Nonmyocytes (mostly fibroblasts) were separated from cardiomyocytes by $90 \mathrm{~min}$ of preplating during which cardiomyocytes did not attach to the culture plates. Cells were grown at $37^{\circ} \mathrm{C}$ in humidified air with 5\% $\mathrm{CO}_{2}$ for four days in Dulbecco's modified Eagle's medium : medium 199 (4:1) (GibcoBRL, The Netherlands) containing 5\% horse and 5\% fetal calf serum (Boehringer Mannheim B.V., The Netherlands), $100 \mathrm{U}$ penicillin/ml and $100 \mu \mathrm{g}$ streptomycin/ml (Boehringer Mannheim B.V., The Netherlands). Confluent cultures were passaged and seeded at a density of $7.5 \times 10^{4}$ cells $/ \mathrm{cm}^{2}$ in $60 \mathrm{~mm}$ culture dishes (Greiner $\mathrm{GmbH}$, Germany). Growth medium was changed every $48 \mathrm{hrs}$ after seeding and experiments were performed 4-5 days after plating of the cells. Cultures were examined routinely for spindle-shaped fibroblasts by phase contrast microscopy. Under the above conditions of isolation and maintenance, cardiomyocytes did not survive, and our cultures showed less than $10 \%$ contamination with other myocardial cell types. Cells were fed serum free medium for $24 \mathrm{hrs}$ prior to the start of incubation. Cells were incubated with [Sar ${ }^{1}$ ]-ANG II acetate salt (Sigma Chemie, Belgium) at an optimal concentration of $100 \mathrm{nM}$ in the culture medium without serum. Incubations were continued for $15,30,45 \mathrm{~min}$ and 1, 2, 4, 8, 16 and $48 \mathrm{hrs}$. Control cells received only serum free culture medium. Experiments were performed at least four times with different cell batches.

\section{Measurement of fibroblast growth and proliferation}

In order to examine the cell proliferation and growth, total cellular protein as well as DNA contents were measured in cardiac fibroblasts in the presence or absence of [Sar ${ }^{1}$ ]-ANG II. 
Equal number of confluent cells in suspension were dispensed in 4 well multi dishes (Nunc, Roskilde, Denmark) and allowed to attach to the surface and fed serum free medium for 24 hrs and thereafter cells were incubated with [Sar ${ }^{1}$ ]-ANG II $(100 \mathrm{nM})$ in serum free culture medium for $1,6,16,24$ and $48 \mathrm{hrs}$. Cells were lysed in $1 \mathrm{~N} \mathrm{NaOH}$ for $24 \mathrm{hrs}$ at $4^{\circ} \mathrm{C}$ and processed for the measurement of protein and DNA contents using bovine serum albumin and calf thymus DNA respectively as standards essentially following the published protocols $\mathrm{s}^{26,27}$.

\section{Isolation of total cellular RNA and Northern blot analysis}

Total RNA was extracted from the cells by the guanidinium thiocynate-phenol-chloroform method of Chomzynski and Sacchi 28 . The RNA concentration was measured by spectrophotometry. For Northern hybridization, $15 \mu \mathrm{g}$ of total RNA was denatured at $65^{\circ} \mathrm{C}$ in formamide and ethidium bromide containing loading buffer and was size fractionated on a $1 \%$ agarose gel containing $2.2 \mathrm{M}$ formaldehyde. Gels were photographed and rinsed in $2 \times S S C$ ( $1 \times S S C=150 \mathrm{mM} \mathrm{NaCl}, 15 \mathrm{mM}$ trisodium citrate) and RNA was transferred to hybond-N membrane (Amersham Nederland B.V., Den Bosch) by vacuum blotting using 10xSSC. Thereafter, filters were air dried and UV cross linked in a gene linker (Bio-Rad Laboratories B.V., The Netherlands) and ribosomal RNA bands were marked under UV light. Blots were hybridized at $42^{\circ} \mathrm{C}$ in a buffer containing $50 \%$ deionized formamide, $1.0 \mathrm{M}$ sodium chloride, $1 \%$ sodium dodecylsulfate (SDS), $0.2 \%$ polyvinyl pyrrolidone, $0.2 \%$ ficoll, $0.2 \%$ bovine serum albumin, $50 \mathrm{mM}$ Tris-HCl (pH 7.5), $0.1 \%$ sodium pyrophosphate, 10\% dextran sulfate and denatured salmon sperm DNA $(100 \mu \mathrm{g} / \mathrm{ml})$. cDNA probes used for hybridization were; rat $\mathrm{c}$ fos $^{11}$ (2.1 kb EcoRI fragment), mouse $c$-jun ${ }^{12}$ (2.6 kb EcoRI fragment), mouse Egr-1 ${ }^{13}$ (300 bp fragment of non zinc finger region) and human TGF- $\beta 1^{29}$ (1050 bp EcoRI fragment). cDNA inserts were labeled employing a multiprime labelling system (Amersham Nederland BV, Den Bosch), to a specific activity of $10^{9} \mathrm{cpm} / \mu \mathrm{g}$ DNA using [ $32 \mathrm{P}$ ]-dCTP (3000 Ci/mmol, Amersham Nederland BV, Den Bosch). After the labelling reaction, probes were purified using nuctrap push columns (Stratagene Inc., USA) to remove unincorporated radioactive dCTP. Filters were washed at room temperature for $5 \mathrm{~min}$ in $2 \times \mathrm{SSC}$ and $0.1 \% \mathrm{SDS}$ and at $55^{\circ} \mathrm{C}$ in $0.1 \times \mathrm{xSC}$ containing $0.1 \%$ SDS for $20 \mathrm{~min}$. Subsequently, filters were wrapped in household plastic wrap and exposed to Kodak X-OMAT AR films (Kodak Nederland B.V., Odijk) at $-80^{\circ} \mathrm{C}$ for $1-3$ days. A glyceraldehyde-3-phosphate dehydrogenase (GAPDH) cDNA probe $(1.2 \mathrm{~kb}$ PstI fragment of human CDNA, procured from ATCC, USA) was used to rehybridize membranes for reference purposes. Hybridization signals on autoradiographs were quantitated by video scanning in optical density mode using a Bioprofil version 4.6 computer program (Vilber Lourmat, France). Several exposures of the Northern blots were taken to ensure that quantitation of hybridization signals was in linear range. For normalization, optical density (OD) of hybridization signal for each gene was divided by OD of the corresponding GAPDH signal. Induction of each gene was expressed as fold induction of mRNA signal (mean+SEM) in ANG II treated cells relative to control (set of 1).Expression was statistically analyzed using student's " $t$ "-test and significance was accepted at $\mathrm{P}<0.05$.

\section{Results and Discussion}

\section{Effect of ANG II on cell proliferation and growth of cardiac fibroblasts}

To evaluate the influence of ANG II on cell proliferation (hyperplasia) and growth (hypertrophy), DNA and protein contents of neonatal cardaic fibroblasts were measured in relation to ANG II stimulation with time. Growth arrested cells by feeding serum free medium for $24 \mathrm{hrs}$ prior to start incubations were used to clearly delineate the effect of ANG II on cellular phenotype. Figure 1 shows the effect of ANG II on the DNA and protein contents of the neonatal cardiac fibroblasts at various time points of incubations. No significant increase in the DNA contents of ANG II treated as compared to the control cells was noticed at any time point up to $48 \mathrm{hrs}$ of incubation, indicating no cell proliferation under these conditions. Our results are 


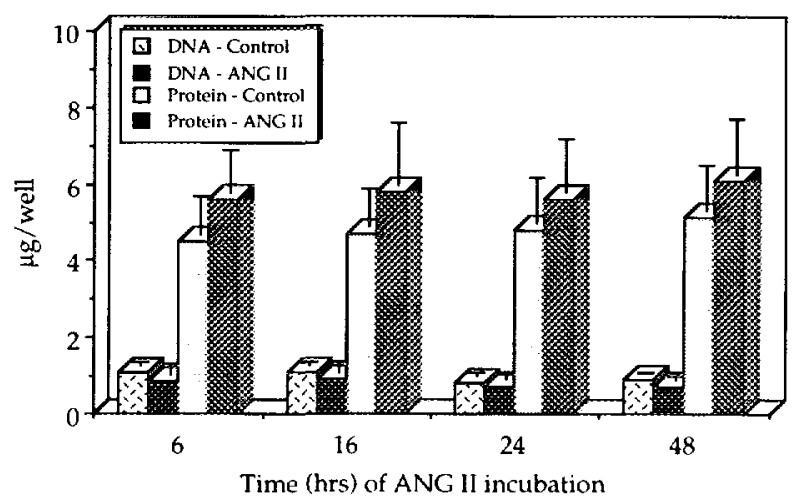

Fig.1. Effect of ANG II on the DNA and protein contents of the neonatal cardiac fibroblasts.

Total DNA and protein contents of neonatal cardiac fibroblasts in the presence and absence of ANG II were measured as described in 'Materials and Methods'. DNA and protein values were calculated from three independent experiments of four determinations each and expressed as $\mu \mathrm{g} /$ well $\pm \mathrm{SEM}$ and $\mu \mathrm{g} /$ well $\pm \mathrm{SEM} \times 10^{-1}$ respectively.

in agreement with other recently reported findings, where no effect of ANG II on proliferation of neonatal as well as adult rat cardiac fibroblasts was observed in serum free conditions $\mathrm{s}^{9,20}$. On the contrary, Sadoshima and Izumo have demonstrated that nonmyocyte fraction of cardiac tissue treated with ANG II ( $10 \mathrm{nM}$ ) in serum free medium showed significantly increased synthesis of protein and DNA over control, but the magnitude of such an increase was lower than the cells fed with serum ${ }^{3}$. Furthermore, we did not observe significant increase in the protein over DNA ratio indicating that ANG II could not induce hypertrophy in neonatal cardiac fibroblasts in culture. However, others have shown for cadiomyocytes that ANG II increases protein synthesis in vitro associated with late hypertrophic response to ANG $\mathrm{II}^{3,10}$.

\section{Expression of transcription factors: An immediate early response to ANG II}

In this study, we examined the expression pattern of three nuclear proto-oncogenes (or TFs); c-fos and c-jun (members of leucine zipper family) and Egr-1 (a member of zinc finger family) which have been widely implicated in cell growth and differentiation $11-17$. Representative Northern blots are shown in Fig. 2. ANG II induced the expression of mRNAs encoding Egr-1 and c-fos as early as $15 \mathrm{~min}$ (Fig. 2A, B), while c-jun expression was increased only after 45 min of ANG II addition to the cultures of serum deprived fibroblasts (Fig. 2C). The induction of Egr-1 and c-fos was transient and reached a maximum at 45 min followed by a sharp decline where as the expression of c-jun was maximal at $60 \mathrm{~min}$ and gradually returned to basal levels after $2 \mathrm{hrs}$ of ANG II incubation. Figure 2D shows a quantitative analysis of multiple Northern blots by scanning densitometry which revealed that the mean induction of Egr-1, c-fos and c-jun mRNAs was $6.5,5.5$ and 2.5 fold respectively as compared to the controls during 45-60 min of ANG II stimulation. A number of stimuli that induce myocardial hypertrophic response e.g. 

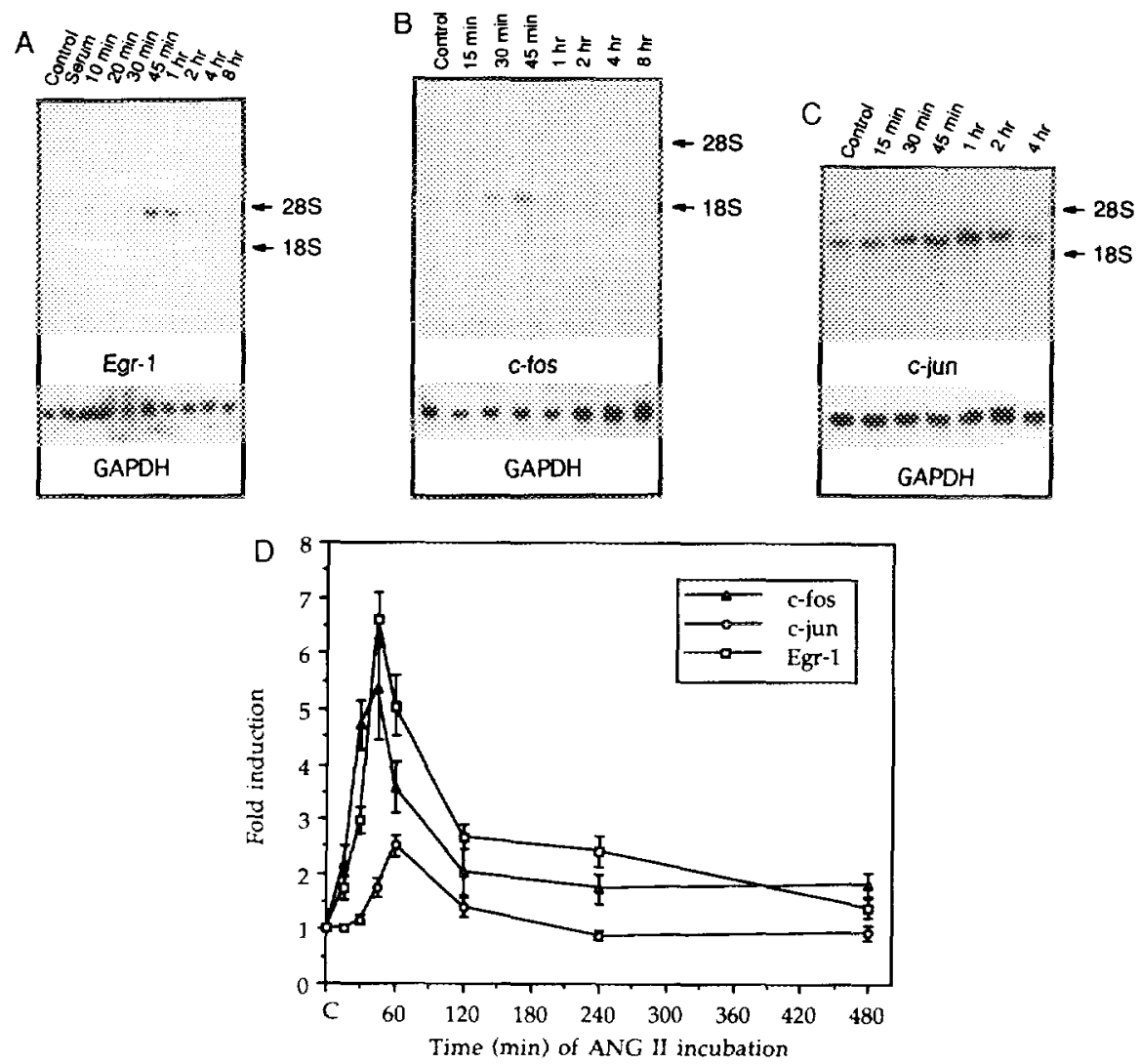

Fig.2. Northern blot analysis of Egr-1, c-fos and c-jun expression in cardiac fibroblasts treated with ANG 11 .

Total RNA $(15 \mu \mathrm{g})$ from control (untreated) and ANG II treated fibroblasts at various time points were subjected to Northern hybridization with radiolabeled cDNA probes for Egr-1, c-fos and $c$-jun as described in 'Materials and Methods'. Representative Northern blots for panel A) Egr-1, B) c-fos, and C) $\mathrm{c}$-jun are shown. Neonatal cardiac fibroblasts were incubated with ANG II $(100 \mathrm{nM})$ in serum free medium for the times indicated on the top. Lane marked with serum depicts RNA preparation from serum fed cells. Rehybridization of each filter with a GAPDH cDNA probe (lower panel) showed that an equal amount of RNA was loaded in each lane. Panel D) Line diagram showing quantitation of mRNA expression of different TFs Scanning densitometric values for each TF were normalized with respective GAPDH mRNA values and expressed as fold induction of mRNA in ANG II stimulated fibroblasts vs control (set as 1.0). Results represent the mean + SEM of 4 independent experiments.

mechanical load, endothelin-1, fibroblast growth factors as well as ANG II can stimulate IE genes as one of the earlier nuclear events which function as mediators of long term cellular response ${ }^{3,15,18-20}$. ANG II induced changes in IE genes in cardiomyocytes and fibroblasts have been shown to be mediated by $\mathrm{AT}_{1}$ receptors ${ }^{3,5.6}$. Hence, the observed enhanced expression of various $\mathrm{TFs}$ in our model could also be mediated via $\mathrm{AT}_{1}$ receptor subtypes which have recently been shown to be present on cultured cardiac fibroblasts. Studying the signal transduction cascade, we and others have shown that ANG II activates the PI cycle by increase in production of diacylglycerol in cardiomyocytes ${ }^{25,31}$ which could also imply for the signal transduction 
pathway in cadiac fibroblasts. Our results on the expression of TFs demonstrate an ANG II induced IE gene reprogramming which may contribute to the long term phenotypic effects in cardiac fibroblasts.

\section{TGF- $\beta 1$ expression as a late response to ANG II}

ANG II induced the expression of TGF- $\beta 1$ in neonatal cardiac fibroblasts after $1 \mathrm{hr}$ and reached maximal levels at $48 \mathrm{hrs}$ of incubation (Fig. 3A). In contrast to the expression pattern of TFs where a rapid decline after $1 \mathrm{hr}$ of ANG II stimulation was noticed, TGF- $\beta 1$ expression remained elevated (Fig. 3A). Two mRNA species of 2.5 and $3.5 \mathrm{~kb}$ encoding TGF- $\beta 1$ were detected in neonatal rat cardiac fibroblasts which are reported previously for the cardiac tissue 30 . Both mRNA species of TGF- $\beta 1$ responded to the ANG II stimulation. Expression of the $3.5 \mathrm{~kb}$ mRNA was gradually increased from an almost non detectable band to a dominant band after 16 hr of ANG II stimulation. Densitometric analysis of both TGF- $\beta 1$ mRNAs showed a significantly increased expression after 4 hrs of stimulation as compared to the control and there after the expression plateaued off but remained elevated about two fold vs control (Fig. 3B). It must be reminded that in this model, we did not see any proliferative or hypertrophic effect of ANG II on cardiac fibroblasts up to $48 \mathrm{hrs}$. Therefore, ANG II induced TGF- $\beta 1$ may not participate in the cellular proliferation but it may rather play a crucial role in the regulation of
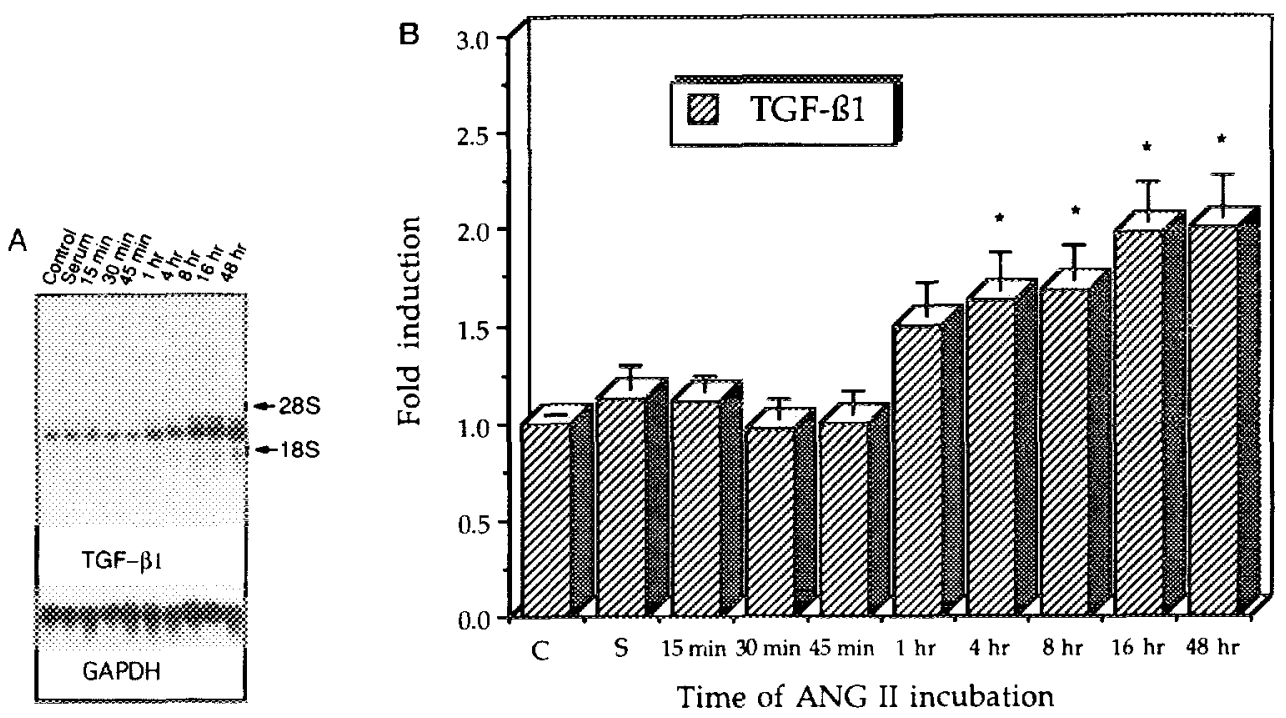

Fig.3. Angiotensin 11 induced expression of TGF- $\beta 1$ in neonatal rat cardiac fibroblasts.

Panel A: A representative Northern blot showing a major 2.5 and a minor $3.5 \mathrm{~kb}$ mRNA band of TGF- $\beta 1$ is depicted. $15 \mu \mathrm{g}$ of total RNA from control and ANG II treated fibroblasts was hybridized with a cDNA insert encoding human TGF- $\beta 1$. Neonatal rat fibroblasts were incubated with ANG II (100 $\mathrm{nM})$ in serum free growth medium for the times indicated on the top. Filters were reprobed with a radiolabeld GAPDH cDNA probe for reference purposes. Panel B: Bar graph showing quantitative analysis of the ANG II induced TGF- $\beta 1$ expression. Hybridization signals from both mRNA bands of TGF- $\beta 1$ as well as from GAPDH blots were quantitated by video densitometry as described in the text. Data are means of the normalized signal + SEM $(n=4)$ and expressed as fold induction vs control. ${ }^{*} \mathrm{P}<0.05$ vs control. 
certain genes involved in the extracellular matrix remodeling. ANG II induced expression of fibronectin and collagen have already been reported in the cardiac fibroblasts ${ }^{7,8}$. Therefore, the induced TGF- $\beta 1$ expression in our model could be attributed to its autocrine role in stimulating the expression of genes encoding extracellular matrix components such as fibronectin and collagens. At present we do not know whether in our model of serum free cultured cardiac fibroblasts, cell proliferation occurs after more than $48 \mathrm{hrs}$ of stimulation and if TGF- $\beta 1$ could play a mediating role.

In this study, we have shown that ANG II directly influence the IE gene reprogramming followed by an induction in a late gene, TGF- $\beta 1$ associated with the extracellular fratrix remodeling. Sadoshima et al. have shown that stretching of cardiomyocytes in serum free medium leads to the production and release of ANG Il in vitro ${ }^{31}$, indicating that the fibrotic response in hypertrophy is in part mediated via a paracrine action of ANG II on cardiac fibroblasts. Furthermore, Neyses et al. have shown that an antisense oligonucleotide for Egr-1 prevented endothelin induced hypertrophic response in adult cardiomyocytes demonstrating the importance of this gene in early phase of cardiac hypertrophy ${ }^{32}$. Several cardiac specific genes including hypertrophic markers like atrial natriuretic factor (ANF) and $\beta$-myosin heavy chain ( $\beta$-MHC) have been identified as transactivated by FOS/JUN heterodimer ${ }^{17.33}$. It is quite possible that TGF- $\beta 1$, among other genes involved in the remodeling of extracellular matrix during hypertrophy are probably targets of transactivation by the gene products of TFs found to be augmented in this study. To prove a functional relation between nuclear proto-oncogene expression and TGF- $\beta 1$ in relation to ANG II, further studies such as antisense constructs, cotransfections with respective promoters would be needed.

\section{References}

1. Griendling, K.K., Murphy, T.J. and Alexander, R.W. (1993) Circulation 87: 1818-1828

2. Schorb, W., Booz, G.W., Dostal, D.E., Conrad, K.M., Chang, K.C. and Baker, K.M. (1993) Circ Res 72: 1245-1254

3. Sadoshima, J. and Izumo, S. (1993) Circ Res 73: 413-423

4. Gibbons, G.H., Pratt, R.E., and Dzau, V.J. (1992) J. Clin. Invest. 90: 456-461

5. Villarreal, F.J., Kim, N.N., Ungab, G.D., Printz, M.P. and Dillmann, W.H. (1993) Circulation 88: 2849-2861

6. Matsubara, H., Kanasaki, M., Murasawa, S., Tsukaguchi, Y., Nio Y. and Inada, M. (1994) J. Clin. Invest. 93: 1592-1601

7. Crabos, M., Roth, M., Hahn A.W.A. and Erne, P. (1994) J. Clin. Invest. 93: 2372-2378

8. Crawford, D.C., Chobanian, A.V. and Brecher, P. (1994) Circ. Res. 74: 727-739

9. Brilla, C.G., Zhou, G., Matsubara, L. and Weber, K.T. (1994) J. Mol. Cell. Cardiol. 26: 809-820

10. Baker, K.M., Booz, G.W. and Dostal, D.E. (1992) Ann. Rev. Physiol. 54: 227-241

11. Curran, T., Gordon, M.B., Rubino, K.L. and Sambucetti, C. (1987) Oncogene 2: 79-84

12. Rysek, R-P., Hirai, S.I., Yaniv, M. and Bravo, R. (1988) Nature 334: 535-537

13. Sukhatme, V.P., Cao, X., Chang, L.C., Tasi-Morris, C.H., Stamenkovich, D., Ferreira, P.C.P., Cohen, D.R., Edwards, S.A., Shows, T.B., Curren, T., Lebeau, M.M. and Adamson, E.D. (1988) Cell 53: 37-43

14. McMahon, A.P., Champian, J.E., McMahon, J.A. and Shukhatme, V.P. (1990) Development 108: 281-287

15. Iwaki, K., Sukhatme, V.P., Shubeita H.E. and Chien K.R. (1990) J. Biol. Chem. 265: 13809-13817

16. Chien, K.R., Knowlton, K.U., Zhu, H. and Chien, S. (1991) FASEB J . 5: 3037-3046 
17. Gupta, M.P., Gupta, M., Zak, R. and Sukhatme, V.P. (1991) J. Biol. Chem. 266: 12813-12816

18. Brand, T., Sharma, H.S. and Schaper, W. (1993) J. Mol. Cell. Cardiol. 25: 1325-1337

19. Neyses, L., Nouskas, J., Luyken, J., Fronhoffs, S., Oberdorf, S., Pfeifer, U., Williams, R.S., Sukhatme, V.P. and Vetter H. (1993) J. Hypertension 11: $927-934$

20. Lee, A.A., Villareal, F. and Dillmann, W. (1993) J. Mol. Cell. Cardiol. 25 (suppl. III): S.43

21. Wollnik, B., Kubisch, C., Maass, A., Vetter, H. and Neyses, L. (1993) Biochem. Biophys. Res.Comm. 194: 642-646

22. MacLanen, W.R., Brand, T. and Schneider, M.D. (1993) Circ. Res. 73: 783-791

23. Koibuchi, Y., Lee, W.S., Gibbons, G.H. and Pratt, R.E. (1993) Hypertension 21: 10461050

24. Yagev, S., Heller, M. and Pinson, A. (1982) In Vitro 20: 893-898

25. Van Heugten, H.A.A., Bezstarosti, K., Dekkers, D.H.W. and Lamers, J.M.J. (1993) J. Mol. Cell. Cardiol. 25: 41-55

26. Bradford, M. (1976) Anal. Biochem. 72: 248-253

27. Lee, G.M., Thornthwaite, J.T. and Rasch. E.M. (1984) Anal. Biochem. 137: 221-226

28. Chomzynski, P. and Sacchi, N. (1987) Anal. Biochem. 162: 156-159

29. Derynck, R., Jarrett, J.A., Chen, E.Y., Eaton, D.H., Bell, J.R., Assoian, R.K., Roberts, A.B., Sporn, M.B. and Goeddel, D.V. (1985) Nature 316: 701-705

30. Wünsch, M., Sharma, H.S., Markert, T.,Bernotal-Danielowski, S., Schott, R.J., Kremer, P., Bleese, N. and Schaper, W. (1991) J. Mol. Cell. Cardiol. 23: 1051-1062

31. Sadoshima, J., Xu, Y., Slayter, H.S. and Izumo, S.(1993) Cell 75: 977-984

32. Neyses, L., Nouskas, J. and Vetter, H. (1991) Biochem. Biophys. Res. Comm. 181: 22-27

33. Koracic-Milivojevic, B. and Gardner, D.G. (1992) Mol. Cell. Biol. 12: 292-301 